\title{
Acute Stress and Gender Effects in Sensory Gating of the Auditory Evoked Potential in Healthy Subjects
}

\author{
Zengyou Xin $\mathbb{D}^{1,}{ }^{1,2}$ Simeng Gu, ${ }^{3,4}$ Wei Wang, ${ }^{5}$ Yi Lei $\mathbb{D}^{3},{ }^{3,6}$ and Hong $\mathrm{Li}^{3,6}$ \\ ${ }^{1}$ School of Education Science, Minnan Normal University, Zhangzhou, Fujian 363000, China \\ ${ }^{2}$ Brain and Cognitive Neuroscience Research Center, Liaoning Normal University, Dalian, Liaoning 116029, China \\ ${ }^{3}$ Institute of Brain and Psychological Sciences, Sichuan Normal University, Chengdu, Sichuan 610060, China \\ ${ }^{4}$ Department Medical Psychology, Jiangsu University Medical School, Zhenjiang, Jiangsu 210023, China \\ ${ }^{5}$ Department of Neurosurgery, University of Rochester Medical Center, Rochester, New York 14643, USA \\ ${ }^{6}$ Center for Language and Brain, Shenzhen Institute of Neuroscience, Shenzhen Key Laboratory of Affective and Social \\ Cognitive Science, School of Psychology, Shenzhen University, Shenzhen, 518060 Guangdong, China
}

Correspondence should be addressed to Yi Lei; leiyi821@vip.sina.com

Received 20 March 2020; Revised 11 February 2021; Accepted 22 February 2021; Published 13 March 2021

Academic Editor: Fang Pan

Copyright (c) 2021 Zengyou Xin et al. This is an open access article distributed under the Creative Commons Attribution License, which permits unrestricted use, distribution, and reproduction in any medium, provided the original work is properly cited.

\begin{abstract}
Sensory gating is a neurophysiological measure of inhibition that is characterized by a reduction in the $\mathrm{P}_{50}, \mathrm{~N}_{100}$, and $\mathrm{P}_{200}$ eventrelated potentials to a repeated identical stimulus. It was proposed that abnormal sensory gating is involved in the neural pathological basis of some severe mental disorders. Since then, the prevailing application of sensory gating measures has been in the study of neuropathology associated with schizophrenia and so on. However, sensory gating is not only trait-like but can be also state-like, and measures of sensory gating seemed to be affected by several factors in healthy subjects. The objective of this work was to clarify the roles of acute stress and gender in sensory gating. Data showed acute stress impaired inhibition of $\mathrm{P}_{50}$ to the second click in the paired-click paradigm without effects on sensory registration leading to worse $\mathrm{P}_{50}$ sensory gating and disrupted attention allocation reflected by attenuated $\mathrm{P}_{200}$ responses than control condition, without gender effects. As for $\mathrm{N}_{100}$ and $\mathrm{P}_{200}$ gating, women showed slightly better than men without effects of acute stress. Data also showed slightly larger $\mathrm{N}_{100}$ amplitudes across clicks and significant larger $\mathrm{P}_{200}$ amplitude to the first click for women, suggesting that women might be more alert than men.
\end{abstract}

\section{Introduction}

Acute stress is a stereotypical and multimodal response to a present or imminent challenge overcharging an organism [1] and causes the release of many stress hormones and neuromodulators (e.g., [2]), which can change cellular properties of large-scale neuronal populations throughout the brain [3]. The common stress induction paradigms in laboratory include cold water pressing (also called cold pressor stress (CPS); e.g., [4]) and the Trier Social Stress Test (TSST; [5]). Sensory gating is the ability of the central nervous system to filter incoming stimuli and protect a person from being flooded with irrelevant information (e.g., [6]). It is typically measured by using a paired-click paradigm. In such a paradigm, the event-related potential $\mathrm{P}_{50}$ is measured during the presentation of two identical clicks with an interstimulus interval (ISI) of $500 \mathrm{~ms}$ and a typical interpair interval (IPI) no less than $8 \mathrm{~s}$ [7]. The attenuation of the $\mathrm{P}_{50}$ amplitude to the second click $\left(S_{2}\right)$, relative to that of the first click $\left(S_{1}\right)$, is the operational definition of gating inhibition (i.e., gating or sensory gating; $[8,9])$. The difference and the ratio between these $\mathrm{P}_{50}$ responses are the means to quantitatively assess gating mechanisms (e.g., [9-11]).

Freedman and colleagues initially demonstrated that schizophrenic patients and their family members fail to exhibit typical $\mathrm{P}_{50}$ response inhibition to $S_{2}$ during a paired-click paradigm (e.g., $[8,12])$. Since then, sensory gating has been one of the foci of psychopathological researches on schizophrenia. Because of the highly replicable results across studies on schizophrenia (e.g., [13-16]) and the findings that filtering deficits also occur in unaffected family members $[17,18], \mathrm{P}_{50}$ filtering has been investigated as a 
TABLE 1: Summary of studies investigating auditory sensory gating concerning gender difference and acute stress effects.

\begin{tabular}{|c|c|c|c|c|}
\hline Study & Subjects & Stress and recording timing & Components & Findings \\
\hline Franks et al. [19] & $22 \mathrm{f}, 21 \mathrm{~m}$ & No acute stress & $\mathrm{P}_{50}$ & $\begin{array}{l}\text { Women showed less suppression of the } \mathrm{P}_{50} \\
\text { than men in a mixed sample of manic } \\
\text { and normal subjects }\end{array}$ \\
\hline $\begin{array}{l}\text { Freedman et al. } \\
{[8,20]}\end{array}$ & $73 \mathrm{f}, 90 \mathrm{~m}$ & No acute stress & $\mathrm{P}_{50}$ & $\begin{array}{c}\text { Women had a higher } \mathrm{P}_{50} \text { amplitude to } S_{1} \text { than } \\
\text { men across all age groups, without gender } \\
\text { differences in } \mathrm{P}_{50} \text { ratios }\end{array}$ \\
\hline Hetrick et al. [10] & $30 \mathrm{f}, 30 \mathrm{~m}$ & No acute stress & $\mathrm{P}_{50}, \mathrm{~N}_{100}, \mathrm{P}_{200}$ & $\begin{array}{c}\text { Women had higher } \mathrm{P}_{50} \text { and } \mathrm{N}_{100} \text { amplitudes to } \\
S_{2} \text { and worse gating for } \mathrm{P}_{50} \text { and } \mathrm{N}_{100} \text { without gender } \\
\text { effects at } \mathrm{P}_{200}\end{array}$ \\
\hline Rasco et al. [21] & $25 \mathrm{f}, 25 \mathrm{~m}$ & No acute stress & $\mathrm{P}_{50}$ & $\begin{array}{l}\text { No gender differences in } \mathrm{P}_{50} \text { amplitudes, latencies, } \\
\text { and sensory gating across all age groups }\end{array}$ \\
\hline Clementz et al. [22] & $15 \mathrm{f}, 25 \mathrm{~m}$ & No acute stress & $\mathrm{P}_{50}, \mathrm{~N}_{100}$ & $\begin{array}{c}\text { No gender differences in } \mathrm{P}_{50} \text { and } \mathrm{N}_{100} \text { amplitudes, } \\
\text { latencies, and sensory gating }\end{array}$ \\
\hline Brinkman et al. [6] & $67 \mathrm{f}, 45 \mathrm{~m}$ & No acute stress & $\mathrm{P}_{50}$ & $\begin{array}{l}\text { No gender differences of } \mathrm{P}_{50} \text { latency, } \\
\text { amplitude, and inhibition across all age groups }\end{array}$ \\
\hline Fuerst et al. [23] & $38 \mathrm{f}, 29 \mathrm{~m}$ & No acute stress & $\mathrm{P}_{50}, \mathrm{~N}_{100}, \mathrm{P}_{200}$ & $\begin{array}{l}\text { Men scored higher than women in } \mathrm{P}_{50}, \mathrm{~N}_{100} \text {, or } \mathrm{P}_{200} \\
\text { amplitude to } S_{1} \text { and in all gating differences }\end{array}$ \\
\hline Lijffijt et al. [24] & $34 \mathrm{f}, 26 \mathrm{~m}$ & No acute stress & $\mathrm{P}_{50}, \mathrm{~N}_{100}, \mathrm{P}_{200}$ & $\begin{array}{c}\text { No gender effects in } \mathrm{P}_{50}, \mathrm{~N}_{100} \text {, or } \mathrm{P}_{200} \text { amplitudes } \\
\text { and sensory gating }\end{array}$ \\
\hline Thomas et al. [25] & $21 \mathrm{f}, 13 \mathrm{~m}$ & No acute stress & $\mathrm{P}_{50}$ & No gender effects in $\mathrm{P}_{50}$ amplitudes and $\mathrm{P}_{50}$ gating ratios \\
\hline $\begin{array}{l}\text { Johnson and } \\
\text { Adler [26] }\end{array}$ & $2 \mathrm{f}, 8 \mathrm{~m}$ & $\begin{array}{l}\text { Immediately after } \\
2 \text { min CPS }\end{array}$ & $\mathrm{P}_{50}$ & $\begin{array}{c}S_{2} \mathrm{P}_{50} \text { amplitude increased, and the gating ratio also } \\
\text { increased, after exposure to CPS }\end{array}$ \\
\hline White et al. [27] & $7 \mathrm{f}, 6 \mathrm{~m}$ & $\begin{array}{l}\text { During mental arithmetic } \\
\text { stressor }\end{array}$ & $\mathrm{P}_{50}$ & $\begin{array}{l}\mathrm{P}_{50} \text { gating was reduced, due to a reduction of } S_{1} \mathrm{P}_{50} \\
\text { amplitude, relative to nonstress task }\end{array}$ \\
\hline Yee et al. [28] & $9 \mathrm{f}, 11 \mathrm{~m}$ & $\begin{array}{l}\text { During mental arithmetic } \\
\text { stressor }\end{array}$ & $\mathrm{P}_{50}$ & $\begin{array}{l}\text { Stressor disrupted P50 sensory gating without } \\
\text { differential } \\
\text { effects on } \mathrm{P}_{50} \text { amplitudes to } S_{1} \text { and } S_{2}\end{array}$ \\
\hline *Ermutlu et al. [29] & $7 \mathrm{f}, 8 \mathrm{~m}$ & During 5 min CPS & $\mathrm{P}_{50}, \mathrm{~N}_{100}$ & $\begin{array}{l}\text { CPS impaired } \mathrm{P}_{50} \text { sensory gating without effect on } \\
\mathrm{N}_{100} \text { gating (deviant/standard) }\end{array}$ \\
\hline Woods et al. [11] & 21f, $9 \mathrm{~m}$ & $\begin{array}{l}\text { Immediately after } \\
50 \mathrm{~s} \text { CPS }\end{array}$ & $\mathrm{P}_{50}$ & $\begin{array}{c}S_{1} \mathrm{P}_{50} \text { amplitude decreased, without effect on } \mathrm{P}_{50} \text { gating } \\
\text { ratio, after exposure to CPS }\end{array}$ \\
\hline Atchley [30] & $20 \mathrm{f}, 10 \mathrm{~m}$ & $\begin{array}{l}\text { Immediately after } \\
2 \text { min CPS }\end{array}$ & $\mathrm{P}_{50}$ & $\mathrm{P}_{50}$ gating ratios increased after CPS \\
\hline White et al. [12] & $13 \mathrm{f}, 16 \mathrm{~m}$ & $\begin{array}{l}\text { During mental } \\
\text { arithmetic stressor }\end{array}$ & $\mathrm{P}_{50}, \mathrm{~N}_{100}$ & $\begin{array}{l}S_{1} \mathrm{P}_{50} \text { was reduced for women, whereas men showed } \\
\text { reductions for both clicks, and women showed } \\
\text { disrupted } \mathrm{P}_{50} \mathrm{~N}_{100} \text { gating whereas men only disrupted } \\
\mathrm{N}_{100} \text { gating, during stress compared to baseline }\end{array}$ \\
\hline
\end{tabular}

${ }^{*}$ Using oddball paradigm; f: female; m: male; CPS: cold pressor stress.

candidate potential endophenotype for schizophrenia. Additionally, in psychopathological studies, there also have been concerns on $\mathrm{N}_{100}$ and $\mathrm{P}_{200}$ sensory gating, which were assessed using event-related potential $\mathrm{N}_{100}$ and $\mathrm{P}_{200}$, respectively. However, as for normative data regarding the characteristics of sensory gating, up till now, relatively limited studies using healthy volunteers have targeted gender and acute stress, respectively, and have reported inconsistent outcomes (see Table 1).

According to previous studies focusing on gender difference, three studies supported less $\mathrm{P}_{50}$ sensory gating for women $[10,19,23]$, and six of the limited documents support no gender difference in $\mathrm{P}_{50}$ sensory gating. The similarly inconsistent findings on the $\mathrm{P}_{50}$ amplitudes for $S_{1}$ or $S_{2}$ were reported between genders. As for the influences of acute stress, although adverse $\mathrm{P}_{50}$ sensory gating effects were reported in almost all studies (except for Woods et al. [11]), there were inconsistent findings on the $\mathrm{P}_{50}$ response to the two clicks after acute stress intervention. As for auditory evoked potential components other than $\mathrm{P}_{50}$, as shown in Table 1, the results of $\mathrm{N}_{100}$ and $\mathrm{P}_{200}$ seemed even more inconsistent.

To date, except for a single study, no attempt has been made to investigate the gender difference in the effects of acute stress on sensory gating. During an oral mental arithmetic stressor task, sensory gating ratios were measured to the paired-click paradigm, and women showed disrupted $\mathrm{P}_{50}$ and $\mathrm{N}_{100}$ gating whereas men exhibited only disrupted $\mathrm{N}_{100}$ gating [12]. Although White et al. reported valuable information, several limitations have to be noted. The first is the protocol used to induce acute stress. According to White et al. [12], $\mathrm{P}_{50}$ data were recorded while mental arithmetic was performing, in which the experimental effect was 
inevitably contaminated by the concurrent working memory task; however, $\mathrm{P}_{50}$ sensory gating was not a complete automatic and preattentive process; it involved top-down modulations and could be influenced by attention manipulation $[16,31,32]$. Furthermore, the muscle artifacts of oral mental arithmetic cannot be ignored. The second is the different interpair intervals (10-14 s for some subjects, while 7-10 s for others), which may deeply affect the $\mathrm{P}_{50}$ response (e.g., [7]), because the sensory gating data were derived from two different studies [27, 28]. The third is numbers of epochs averaged (80 trials for data from White and Yee [27], 60 trials from Yee and White [28]), and the fourth is limited sample size (13 women and 16 men), in addition to some differences in experimental procedures.

Thus, the main objective of this study was to further investigate possible gender differences in the sensory gating after exposure to stressful treatment or control condition. It has been reported that the fluctuation of sex steroid hormone during menstrual cycles affects the performance of working memory [33], proponent response inhibition [34], arousal state [35], and fear conditioning and inhibition [36] in healthy women. Thus, only women during their midluteal phase were included to control the potential effects of menstrual cycle. A body of literature suggests the major neural sources of $\mathrm{P}_{50}$ suppression involves the hippocampus and prefrontal cortex (e.g., $[9,37,38])$, where stress hormone receptors are abundant and stress exerts effects on cognitive processes (e.g., $[3,39,40]$ ). Therefore, sensory gating under acute stress would therefore be expected to be impaired. Additionally, it has been supposed that two processes contribute to the gating deficit, i.e., a reduced sensory registration $\left(S_{1}\right.$ amplitude reduction) and a reduced ability to inhibit the repeated auditory stimulation (lack of reduction of $S_{2}$ amplitude; e.g., [41-43]). Sensory registration and suppression may be differentially affected by acute stress and may show gender difference meanwhile. Thus, another aim of this study is to determine which one plays a big role in the gender and acute stress effects. Given that fewer studies using paired-click paradigm focused on $\mathrm{N}_{100}$ and $\mathrm{P}_{200}$ gating, an exploratory investigation was also made in the current study.

\section{Method}

2.1. Participants. Forty-three healthy university students $(25$ males, 18 females) were included in the study. One female subject dropped out, data of a male subject was incomplete because of technical failure, and another female was excluded because of failure to obtain reliable $\mathrm{P}_{50}$ response in CPS experimental session. Thus, data were from 24 men (ranged in age from 20 to 23 years, mean $=21.3, \mathrm{SD}=0.86$ ) and 16 women (for $\mathrm{N}_{100}$ and $\mathrm{P}_{200}$ data; ranged from 19 to 23; mean $=20.76, S D=0.97)$. Statistical results of 16 women other than $\mathrm{P}_{50}$ data would not be present in the paper because there was no significant difference from 17-woman sample that were included in the analyses. Only women during their midluteal phase (with regular menstrual cycles, days 16 to 24) were included to control possible gender and ovarian cycle effects on adrenocortical reactivity [44, 45]. Participants were asked to refrain from caffeine, alcohol, tea, and smoking within $6 \mathrm{~h}$ before the experimental sessions. The volunteers were recruited by announcements and received financial compensation. The study was approved by the Ethics Committee of the Minnan Normal University. All participants were naive to the purpose of the study and gave their written informed consent prior to their inclusion in the study.

2.2. Procedure. After a participant's arrival, he or she was allowed to rest briefly, and then, preexperimental saliva sample (to measure cortisol level) was taken, and systolic blood pressure (SBP), diastolic blood pressure (DBP), and heart rate (HR) were recorded at the same time to evaluate participant's physical baseline. Then, participants filled out the Positive and Negative Affect Schedule (PANAS; [46]), Beck Depression Inventory-Second Edition (BDI-II; [47]), and Anxiety Inventory [48]. Data of Trait Anxiety Inventory was collected during their first experimental session. Then, participants were exposed to either the CPS treatment or the warm water (control) treatment (adapted from) [4]. Immediately after treatment, all subjects had a rest, and then SBP, DBP, and HR were measured at about $4 \mathrm{~min}$ after CPS or control procedures. Then, subjects were engaged in the experimental task, and meanwhile, EEG data was collected. Further, saliva samples were taken immediately after the task (about $15 \mathrm{~min}$ after treatment). The method of salivary cortisol measurement was described in Yang et al. [49]. All salivary samples were stored at $-40^{\circ} \mathrm{C}$, and analyses were completed within about one month.

This experiment was conducted by adopting a withinsubjects design, in which CPS and control procedures were, respectively, applied by an interval of at least $24 \mathrm{~h}$, and treatment order was counterbalanced. Subjects were instructed to submerge their hands and wrists in cold water $\left(6^{\circ}\right.$ to $\left.9^{\circ} \mathrm{C}\right)$ for $5 \mathrm{~min}$ for CPS session while in warm water $\left(35^{\circ}\right.$ to $\left.38^{\circ} \mathrm{C}\right)$ during control session (adapted from [4]). To avoid any influence of the circadian profiles of adrenocortical reactivity and cognitive ability, CPS or control procedures were conducted in the same time period of the experiment day and the other experimental procedures were the very same.

\subsection{Stimuli and EEG Recording and Analysis}

2.3.1. Auditory Stimulation. About $5 \mathrm{~min}$ after treatment, paired clicks of $2000 \mathrm{~Hz}, 95 \mathrm{~dB}$ SPL tones, and $4 \mathrm{~ms}$ in duration were delivered via headphones with $50 \mathrm{~dB}$ SPL background white noise. The sound intensity was measured at the subject's ear by a sound meter. All 60 paired clicks were separated by a $500 \mathrm{~ms}$ interval, and interpair interval was random ranged from 7.5 to $10 \mathrm{~s}$ in order to allow brain activity to return to baseline (e.g., $[6,7])$.

2.3.2. EEG Recording. Participants were seated in a comfortable chair in an electromagnetically shielded room, wearing headphones, and instructed to sit comfortably and still, close their eyes, relax, and listen to clicks. All subjects were monitored for signs of drowsiness by visual observation and EEG monitoring because $\mathrm{P}_{50}$ component is sleep-state dependent (e.g., [11]). Brain electrical activity was recorded at $\mathrm{F}_{\mathrm{z}}, \mathrm{C}_{\mathrm{z}}$, $\mathrm{P}_{\mathrm{z}}, \mathrm{F}_{3}, \mathrm{~F}_{4}, \mathrm{C}_{3}, \mathrm{C}_{4}, \mathrm{O}_{1}$, and $\mathrm{O}_{2}$ sites using $\mathrm{Ag} / \mathrm{AgCl}$ electrodes mounted on an elastic cap (Brain Product, München, 
Germany), with references on $\mathrm{FC}_{\mathrm{z}}$, and a ground electrode on the medial frontal aspect. Vertical electrooculograms (EOGs) were recorded supra- and infraorbitally at the left eye. The horizontal EOG was recorded from the left versus right orbital rim. The EEG and EOG were amplified using a 0.05 to $100 \mathrm{~Hz}$ bandpass and were continuously digitized at $1000 \mathrm{~Hz} /$ channel during online recording. All interelectrode impedances were maintained below $5 \mathrm{k} \Omega$.

2.3.3. EEG Analysis. Offline, the data were referenced to the average of the left and right mastoids, digitally filtered at $10-50 \mathrm{~Hz}$ for $\mathrm{P}_{50}$ and $1-30 \mathrm{~Hz}$ for $\mathrm{N}_{100}$ and $\mathrm{P}_{200}$, a $50 \mathrm{~Hz}$ notch filter and both a roll-off of $24 \mathrm{~dB}$ /octave, segmented ( -100 to $200 \mathrm{~ms}$ for $\mathrm{P}_{50} ;-100$ to $400 \mathrm{~ms}$ for $\mathrm{N}_{100}$ and $\mathrm{P}_{200}$ ), and baseline-corrected $(100 \mathrm{~ms})$. Trials containing artifacts (activity in any channel exceeded $75 \mu \mathrm{V}$ ) were removed from further analyses. Totally, $75-100 \%$ of the epochs (45-60 trials) were included in the $\mathrm{N}_{100}$ and $\mathrm{P}_{200}$ analyses and 77$100 \%$ (46-60 trials) for $\mathrm{P}_{50}$. There is no statistical difference in number of epochs of each condition.

After averaging, according to the procedures of former studies (e.g., $[11,12,16,27,38]$ ), latencies and amplitudes of the $\mathrm{P}_{30}, \mathrm{~N}_{40}, \mathrm{P}_{50}, \mathrm{~N}_{100}$, and $\mathrm{P}_{200}$ at $\mathrm{C}_{\mathrm{z}}$ were analyzed on the basis of automatic peak detection in combination with a visual inspection according to the waveforms drawn using Excel 2007. The $\mathrm{P}_{50}$ component was defined as the most positive response between 45 and $90 \mathrm{~ms}$ poststimulus preceded by a $\mathrm{P}_{30}$ wave in a $15-45 \mathrm{~ms}$ range. The $\mathrm{N}_{100}$ and $\mathrm{P}_{200}$ component was defined as a prominent negative-positive complex $\left(\mathrm{N}_{100}: 80-180 \mathrm{~ms}, \mathrm{P}_{200}: 120-250 \mathrm{~ms}\right) . \mathrm{P}_{50}$ amplitude was normally measured relative to the $\mathrm{N}_{40}$ (defined as the most negative response between $\mathrm{P}_{30}$ and $\mathrm{P}_{50}$ latencies; if no identifiable $\mathrm{P}_{30}$, then between $30 \mathrm{~ms}$ and $\mathrm{P}_{50}$ latency). If no identifiable $\mathrm{N}_{40}$ happened under any condition, all $\mathrm{P}_{50}$ amplitudes of this subject were measured relative to the prestimulus baseline, and this solution was also used in case of negative $\mathrm{P}_{50}$ gating ratios. $\mathrm{N}_{100}$ and $\mathrm{P}_{200}$ amplitudes were measured relative to the prestimulus baseline. As for components of $S_{2}$, they were additionally determined by reference to the $S_{1}$ component latencies (i.e., $\pm 15 \mathrm{~ms}$ away from latency of $S_{1} \mathrm{P}_{50}$ for $S_{2}$ $\mathrm{P}_{50}, \pm 30 \mathrm{~ms}$ for $S_{2} \mathrm{~N}_{100}$ and $\pm 35 \mathrm{~ms}$ for $S_{2} \mathrm{P}_{200}$ ). When no amplitude was identifiable for $S_{1}$, the subject's response was excluded from further analysis (one case for $\mathrm{P}_{50}$ ). If this was the case for $S_{2}$, it was interpreted as maximum suppression and the amplitude was set to zero in accordance [50]. Gating indices were calculated as gating ratio $\left(S_{2} / S_{1} \times 100\right)$ as well as gating difference $\left(S_{1}-S_{2}\right)$.

\section{Results}

3.1. Mood, Trait Anxiety, and Physiological Measurements. Results of trait anxiety test demonstrated no difference between males $(M=40.5, \mathrm{SD}=4.7)$ and females $(M=40.8$, $\mathrm{SD}=4.9, p=0.85)$. To evaluate potential differences in baseline mood variables (positive and negative affect, state anxiety, and depression), mixed measure ANOVAs were conducted with treatment (CPS vs. control) as a withinsubjects factor and gender as a between-subjects factor. The ANOVA showed no main effects of gender $(p=0.86,0.29$,
0.48 , and 0.59 , respectively), treatment $(p=0.44,0.64,0.24$, and 0.77 , respectively), and no interactions $(p=0.99,0.22$, 0.22 , and 0.88 , respectively) (Table 2 ). Mixed measure ANOVAs were also conducted on cardiovascular and cortisol reactivity with two within-subjects factors: treatment (CPS vs. control) and timing (baseline and after treatment) and gender as another factor to evaluate the effect of experimental manipulation. The results showed significant main effects of treatment in $\operatorname{HR}[F(1,39)=14.13, p=0.001, \eta 2 \mathrm{p}=0.27]$, DBP $\quad[F(1,39)=16.30, \quad p<0.001, \quad \eta 2 \mathrm{p}=0.30], \quad$ SBP $[F(1,39)=11.25, p=0.002, \eta 2 \mathrm{p}=0.22]$, and cortisol concentrations $[F(1,39)=7.09, p=0.011, \eta 2 \mathrm{p}=0.15]$ and significant main effects of gender. Specifically, data showed significantly higher HR $(p=0.026)$ and cortisol concentrations $(p=0.024)$ for females, while higher DBP $(p=0.051)$ and SBP $(p<0.001)$ for males. The results also showed significant interactions of treatment $\times$ timing to DBP $[F(1,39)=7.50, \quad p=0.009, \quad \eta 2 \mathrm{p}=0.16], \quad$ SBP $[F(1,39)=6.02, \quad p=0.019, \quad \eta 2 \mathrm{p}=0.13], \quad$ and cortisol $[F(1,39)=13.0, p=0.001, \eta 2 \mathrm{p}=0.25]$. Further analysis showed no difference of blood pressures between baseline and after-treatment data during control session while in CPS session there were significantly higher after-treatment DBP $(p<0.001)$, SBP $(p=0.002)$, and cortisol concentrations $(p=0.001)$, relative to baseline data.

3.2. $P_{50}$ Latencies, Amplitudes, and Sensory Gating. The grand averaged auditory evoked potentials for both genders, during two experimental sessions, are presented in Figure 1, and descriptive results on $\mathrm{P}_{50}$ measures can be found in Table 3 . $\mathrm{P}_{50}$ amplitudes and latencies to peak were evaluated by performing separate 2 (gender) $\times 2$ (stimuli: $S_{1}$ vs. $\left.S_{2}\right) \times 2$ (treatment: CPS vs. control) mixed measure ANOVAs. The ANOVA showed the $\mathrm{P}_{50}$ latencies did not show any main effects and interactions (all $p>0.14$ ). However, the $\mathrm{P}_{50}$ amplitudes showed a significant main effect of stimuli $[F(1,38)=25.29, p<0.001, \eta 2 \mathrm{p}=0.40]$ and a significant interaction of stimuli $\times$ treatment $[F(1,38)=17.18, p<$ $0.001, \eta 2 \mathrm{p}=0.31]$, but no main effect of gender or other interactions. Further analysis showed $\mathrm{P}_{50}$ amplitude to $S_{2}$ during CPS experimental session was significantly larger than that to $S_{2}$ during control session $(p=0.01)$, while there is no difference for $\mathrm{P}_{50}$ amplitude to $S_{1}$ between two sessions. Additionally, $\mathrm{P}_{50}$ amplitude to $S_{1}$ was significantly larger than that to $S_{2}$ for both sessions $(p=0.037$ for CPS and $p<$ 0.001 for control).

$\mathrm{P}_{50}$ gating ratios and gating difference were evaluated by performing 2 (gender) $\times 2$ (treatment) mixed measure ANOVAs. The results showed no gender main effect $(p=0.79)$ and interaction $(p=0.85)$, but a significant main effect of treatment $[F(1,38)=9.72, p=0.003, \eta 2 \mathrm{p}=0.20]$ for gating ratios. As for gating difference, the same results were obtained, which showed a better gating function after control procedures than that of CPS $[F(1,38)=17.18, p<0.001, \eta$ $2 \mathrm{p}=0.31]$, without gender effect $(p=0.77)$ and interaction $(p=0.93)$.

3.3. $N_{100}$ Latencies, Amplitudes, and Sensory Gating. The grand averaged potentials are presented in Figure 2, and 
TABLE 2: Preexperiment mood and physiological measurements before and after control or CPS treatment.

\begin{tabular}{|c|c|c|c|c|c|c|c|}
\hline & Gender & Positive affect & Negative affect & State anxiety & Depression & Baseline HR & HR after $4 \mathrm{~min}$ \\
\hline \multirow{2}{*}{$\mathrm{CON}(M, \mathrm{SD})$} & Male & $29.3(8.3)$ & $16.1(5.1)$ & $35.9(8.4)$ & $6.9(6.2)$ & $69(13)$ & $66(16)$ \\
\hline & Female & $28.9(8.0)$ & $18.6(5.3)$ & $35.2(8.8)$ & $7.9(6.5)$ & $75(8)$ & $73(11)$ \\
\hline \multirow{2}{*}{$\mathrm{CPS}(M, \mathrm{SD})$} & Male & $30.0(6.8)$ & $16.7(4.6)$ & $36.0(7.4)$ & $7.3(5.4)$ & $62(11)$ & $61(9)$ \\
\hline & Female & $29.6(7.8)$ & $17.3(5.4)$ & $33.0(9.4)$ & $8.1(4.9)$ & $70(9)$ & $67(10)$ \\
\hline \multirow{3}{*}{$\mathrm{CON}(M, \mathrm{SD})$} & Gender & Baseline DBP & DBP after $4 \mathrm{~min}$ & Baseline SBP & SBP after $4 \mathrm{~min}$ & Baseline CORT & CORT after $15 \mathrm{~min}$ \\
\hline & Male & $63(6)$ & $63(5)$ & $112(9)$ & $111(9)$ & $5.0(1.6)$ & $5.0(1.5)$ \\
\hline & Female & $62(6)$ & $61(4)$ & $101(10)$ & $100(7)$ & $6.2(2.1)$ & $6.1(2.0)$ \\
\hline \multirow{2}{*}{ CPS $(M, S D)$} & Male & $67(6)$ & $69(7)$ & $115(7)$ & $116(7)$ & $5.8(1.5)$ & $6.1(1.7)$ \\
\hline & Female & $62(5)$ & $66(5)$ & $101(7)$ & $105(7)$ & $6.6(1.8)$ & $7.3(2.3)$ \\
\hline
\end{tabular}

Values represent means $(M)$ and standard deviations (SD); CON: control condition; CPS: cold pressor stress; HR: heart rate (beats per minute); DBP: diastolic blood pressure (mmHg); SBP: systolic blood pressure (mmHg); CORT: cortisol (nmol/L).

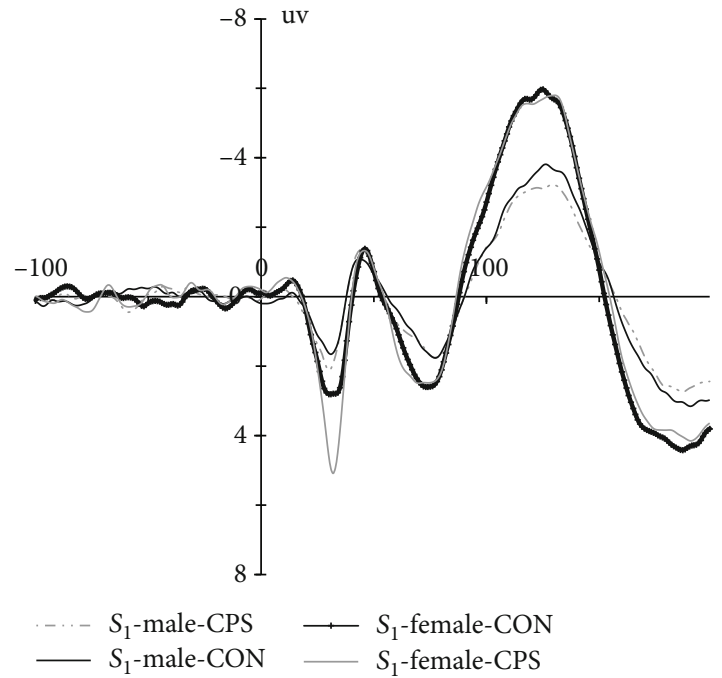

(a)

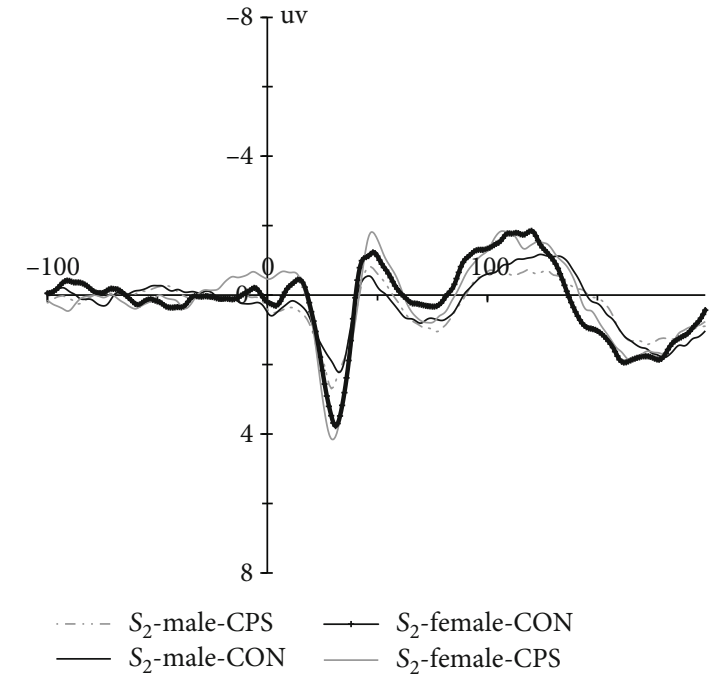

(b)

Figure 1: Grand averaged auditory evoked potential waves $\left(\mathrm{C}_{\mathrm{z}}\right)$ elicited by paired clicks ((a) $S_{1}$, (b) $\left.S_{2}\right)$ for both genders during two experimental sessions (CON: control condition; CPS: cold pressor stress treatment) (bandpass filter $=10-50 \mathrm{~Hz}$ ).

TABle 3: Amplitudes, latencies, gating ratios, and differences for $\mathrm{P}_{50}, \mathrm{~N}_{100}$, and $\mathrm{P}_{200}, M(\mathrm{SD})$.

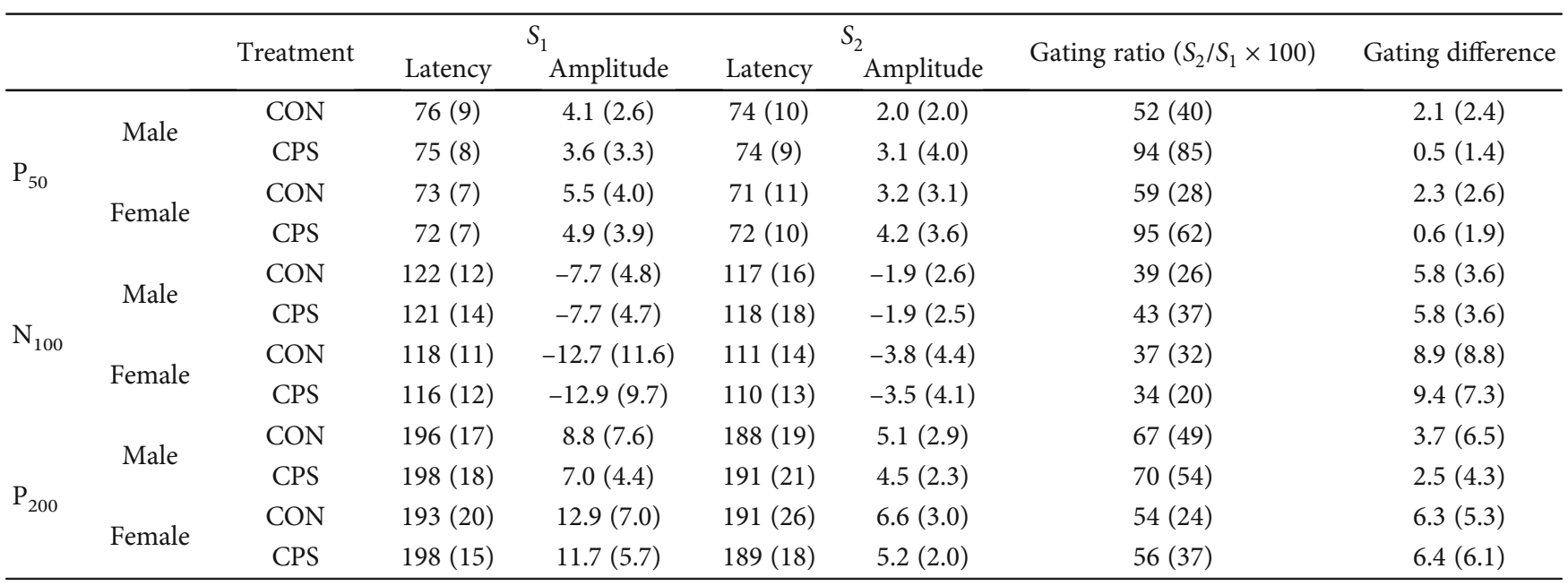




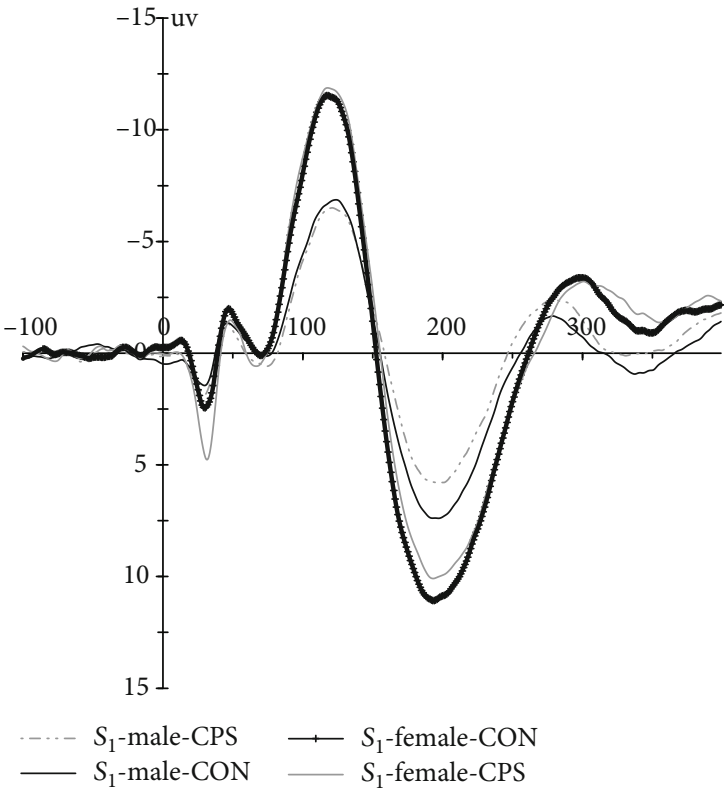

(a)

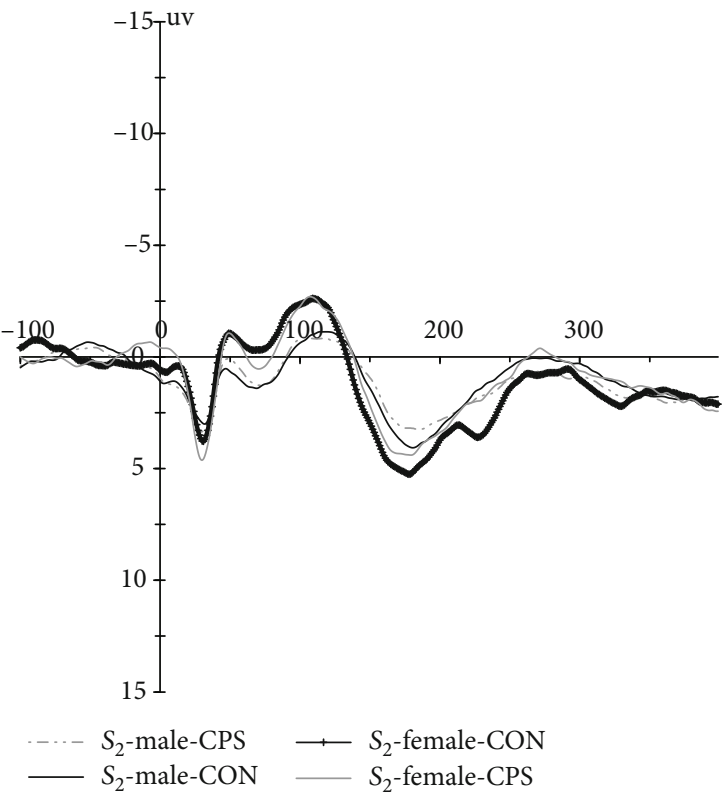

(b)

Figure 2: Grand averaged auditory evoked potential waveforms $\left(\mathrm{C}_{\mathrm{z}}\right)$ elicited by paired clicks ((a) $S_{1}$, (b) $\left.S_{2}\right)$ for both genders during two experimental sessions (bandpass filter $=1-30 \mathrm{~Hz}$ ).

descriptive results on $\mathrm{N}_{100}$ are shown in Table $3 . \mathrm{N}_{100}$ amplitudes and latencies were evaluated by performing separate 2 (gender) $\times 2$ (stimuli: $S_{1}$ vs. $\left.S_{2}\right) \times 2$ (treatment: CPS vs. control) mixed measure ANOVAs.

According to the ANOVA, there was a significant main effect of stimuli with longer latencies for $S_{1}$ than $S_{2}$ $[F(1,39)=6.63, p=0.014, \eta 2 \mathrm{p}=0.15]$ and a borderline main effect of gender $[F(1,39)=3.39, p=0.073, \eta 2 \mathrm{p}=$ 0.08 ], with slightly longer latencies for males than females, but there was no main effect of treatment and no interactions on latency (all $p>0.67$ ). The results also showed a significant main effect of stimuli $[F(1,39)=80.92, p<0.001, \eta 2 \mathrm{p}=$ $\left.0.68, S_{1}>S_{2}\right]$ and of gender $[F(1,39)=5.14, p=0.029, \eta 2 \mathrm{p}$ $=0.12$, larger for females than males] for the mean $\mathrm{N}_{100}$ amplitudes and a borderline significant interaction of stimuli $\times$ gender $\quad[F(1,39)=4.04, \quad p=0.05, \quad \eta 2 \mathrm{p}=0.09]$ without treatment effect. Further analysis showed relatively larger $\mathrm{N}_{100}$ amplitudes in women than men for $S_{1}$ $(p=0.028)$ and $S_{2}(p=0.077)$.

$\mathrm{N}_{100}$ gating ratios and gating difference were evaluated by performing 2 (gender) $\times 2$ (treatment) mixed measure ANOVAs. The results showed no main effects of gender $(p=0.50)$ and treatment $(p=0.99)$ and no interaction $(p=0.51)$ for gating ratios. The data showed similar results for gating difference, but a borderline main effect of gender $[F(1,39)=4.04, p=0.05, \eta 2 \mathrm{p}=0.09]$, with slightly better $\mathrm{N}_{100}$ gating function for females.

3.4. $P_{200}$ Latencies, Amplitudes, and Sensory Gating. The grand averaged potentials are presented in Figure 2, and descriptive results of $\mathrm{P}_{200}$ can be found in Table $3 . \mathrm{P}_{200}$ amplitudes and latencies were evaluated by performing 2 (gender) $\times 2$ (stimuli) $\times 2$ (treatment) mixed measure ANO-
VAs. As for latencies, there was only a significant main effect of stimuli $[F(1,39)=9.31, p=0.004, \eta 2 \mathrm{p}=0.19]$, with longer $\mathrm{P}_{200}$ latencies for $S_{1}$ than $S_{2}$. As for $\mathrm{P}_{200}$ amplitudes, the results showed there were significant main effects of treatment $[F(1,39)=4.43, \quad p=0.042, \quad \eta 2 \mathrm{p}=0.10]$, stimuli $[F(1,39)=37.89, \quad p<0.001, \quad \eta 2 \mathrm{p}=0.49], \quad$ and gender $[F(1,39)=6.34, p=0.016, \eta 2 \mathrm{p}=0.14]$ and a significant interaction of stimuli $\times$ gender $[F(1,39)=4.47, p=0.041, \eta$ $2 \mathrm{p}=0.10]$. Further analysis showed $\mathrm{P}_{200}$ responses were attenuated under CPS than control condition $(p=0.042)$, and females had significantly larger $S_{1} \mathrm{P}_{200}$ amplitude than males $(p=0.018)$, but there was no notable difference in $S_{2}$ response amplitude between genders $(p=0.10)$.

$\mathrm{P}_{200}$ gating ratios and gating difference were evaluated by performing 2 (gender) $\times 2$ (treatment) mixed measure ANOVAs. The results showed no main effects of gender $(p=0.26)$ and treatment $(p=0.77)$ and no interaction $(p=0.90)$ for gating ratios. The data showed similar results for gating differences, but a significant gender effect $[F(1,39)=4.47, p=0.041, \eta 2$ $\mathrm{p}=0.10$, with better $\mathrm{P}_{200}$ gating function for females.

\section{Discussion}

To characterize the response to the CPS, salivary cortisol and cardiovascular response were assessed. The results revealed significantly higher blood pressures, as well as an increased activity of the hypothalamus-pituitary-adrenal axis (reflected by higher cortisol concentrations) after CPS treatment, compared to the control procedure session. The findings are well in line with the previous studies (e.g., $[4,51]$ ) and indicate the successful induction of a neuroendocrine stress response [1]. Moreover, a comparable basis was demonstrated by the baseline psychological measures across all conditions. 
In the paired-click paradigm, sensory gating is operationally defined as the ratio of the amplitude of the response to $S_{2}$ divided by that of $S_{1}$ or the amplitude difference between the two clicks (e.g., [9-11]). Higher ratios and smaller absolute difference values mean worse sensory gating, which could be a result of lower amplitudes in response to $S_{1}$, thus weaker registration functions, or higher amplitudes in response to $S_{2}$, thus weaker inhibition with repetition, according to some authors (e.g., [41-43]). In this view, this study showed diminished $\mathrm{P}_{50}$ gating due to enhanced amplitudes to $S_{2}$ significantly under CPS relative to control condition, while $\mathrm{P}_{50}$ amplitudes to $S_{1}$ remaining unaffected, which indicated that CPS disrupted subjects' capacity of inhibition with repetition, but not sensory registration. These results were in right accordance with Johnson and Adler [26] and Atchley [30]. In addition, Ermutlu et al. [29] used an oddball paradigm and also found CPS impaired $\mathrm{P}_{50}$ sensory gating. As for Woods et al. [11] reporting no evidence on impairment in $\mathrm{P}_{50}$ gating, the most likely explanation is that the CPS procedure used in that study was so weak as only 50 seconds of immersing in cold water that the stress stimuli may not be strong enough to trigger the abundant releasing of norepinephrine (NE) and cortisol to disrupt the sensory gating. A much stronger CPS procedure was used in the current study, and both data of blood pressures and saliva samples proved successful induction of a neuroendocrine stress response. As was known, acute stress can lead to the release of NE from widely distributed synapses, including abundant projections to the PFC, and the rapid activation of the prefrontal dopamine system, and on a slightly longer time scale, the release of cortisol, whose receptors are also abundant in the PFC $[3,39,40,52]$. However, it was proposed that PFC should be the major neural source of $\mathrm{P}_{50}$ suppression by many documents (e.g., $[9,38,53-56])$. Thus, it is reasonable that acute stress disrupts $\mathrm{P}_{50}$ sensory gating via the adverse effects of stress hormones and neuromodulators on PFC which might result in impairments of the inhibition of redundant information.

However, White and Yee [27] reported a reduction of $S_{1}$ $\mathrm{P}_{50}$ amplitude during mental arithmetic stressor, which are different from the results of Johnson and Adler [26], Atchley [30] and the current study that acute stress resulted in an increase of $S_{2} \mathrm{P}_{50}$ amplitude with unchanged $S_{1} \mathrm{P}_{50}$ amplitude. Given that consciously directing attention toward the clicks enhanced $\mathrm{P}_{50}$ amplitude in healthy subjects (e.g., [16, $31]$ ), oral mental arithmetic stressor task during passively listening task makes less attention resources switched to the clicks and might then a reduction of $S_{1} \mathrm{P}_{50}$ amplitude, while in the cases of Johnson and Adler [26], Atchley [30] and the current study, CPS was used to induce stress state and there was no specific cognitive processes involved.

No gender difference in $\mathrm{P}_{50}$ amplitudes and sensory gating was reported in the current study, which was in accordance with previous studies [6, 22 21, 24, 25]. Freedman, Adler, and Waldo [20] also reported no gender difference in $\mathrm{P}_{50}$ sensory gating, but they found women had higher $\mathrm{P}_{50}$ amplitude to $S_{1}$ than men. However, Franks et al. [19] and Hetrick et al. [10] reported women had significantly larger $\mathrm{P}_{50}$ responses to $S_{2}$, but Fuerst et al. [23] reported men scored higher than women in $\mathrm{P}_{50}$ amplitude to $S_{1}$. It is not likely to interpret the discrepancy properly by gender difference in the neuroanatomical origins of the auditory $\mathrm{P}_{50}$ response and inhibition, because it was documented that there was no known gender difference in brain structures or neuronal systems relevant to $\mathrm{P}_{50}$, such as auditory cortex, thalamus, and PFC ([57]; e.g., $[9,10])$, and the discrepancy is mostly state dependent. As mentioned earlier, menstrual cycles could affect several cognitive processing. In particular, Goldstein et al. $[35,58]$ found menstrual cycle modulated women's arousal state with less cortical control over the amygdala during early follicular due to low level of estrogen, but an attenuation of brain activity during midcycle in the presence of higher levels of estrogen. Therefore, given different arousals leading to different baseline $\mathrm{P}_{50}$ responses [11, 59] and the interplay between acute stress and sex steroid hormone (for a review, see [60]), the mechanisms under the discrepancy is more likely estrogen level dependent.

The results of the current study showed no gender difference in the CPS effects on $\mathrm{P}_{50}$ amplitudes and sensory gating. However, White et al. [12] reported a significant gender difference with a significantly reduced $\mathrm{P}_{50}$ to $S_{1}$ but not $S_{2}$ during mental arithmetic stressor for women, not for men, but they did not report any information about menstrual cycles. Therefore, in addition to the defects in design mentioned earlier, the most likely explanation would be that more early follicular phase women participated in that study, while female subjects used in the current study were all in their midluteal phase (days 16 to 24) during which there was a steady rise in estrogen levels forming a second estrogen peak in menstrual cycles [61] and then women might be more comparable to men in arousal and sensory gating because of more cortical control over the amygdala due to high level of estrogen. Future studies should select healthy female subjects during their different menstrual cycles based on direct measurements of gonadal hormone levels instead of selfreported data to precisely determine menstrual phases to further confirm and extend the present findings.

As reviewed earlier, relatively fewer studies using pairedclick procedure focused on $\mathrm{N}_{100}$ and $\mathrm{P}_{200}$ sensory gating. And the relevant findings were also inconsistent. According to Hetrick et al. [10], women had significantly higher $\mathrm{N}_{100}$ amplitudes to $S_{2}$ and worse $\mathrm{N}_{100}$ sensory gating compared to men, but no significant differences were found at $\mathrm{P}_{200}$, and Fuerst et al. [23] found that men had larger $\mathrm{N}_{100}$ and $\mathrm{P}_{200}$ amplitude to $S_{1}$ and better $\mathrm{N}_{100}$ and $\mathrm{P}_{200}$ sensory gating relative to women. However, other studies reported no gender difference $[22,24]$. Data of the current study showed women had larger $S_{1} \mathrm{~N}_{100}$ and $\mathrm{P}_{200}$ amplitudes to $S_{1}$ and better $\mathrm{N}_{100}$ and $\mathrm{P}_{200}$ gating function. In addition to the possible effects of arousal due to fluctuations of gonadal hormones mentioned earlier, potential manipulation of attention because of nonstandardized instructions across studies might be an alternative interpretation. Gjini et al. [31] reported attention status had a significant effect on $\mathrm{N}_{100}$ and $\mathrm{P}_{200}$ amplitudes and gating. However, there is no specific control for attention factors, according to typical instructions in paired-click paradigms. For example, subjects are usually requested to remain awake and try to decrease their eye 
movements, close (e.g., [10] and the current study) or open eyes, fixate on an object (e.g., [22]) or not, listen passively or intently to clicks (e.g., $[22,24])$, keep relaxed or not, and so on. Thus, different baseline attention status due to different emphases in instructions, combined and interacted with fluctuations of gonadal hormones, leads to complex results.

Some studies suggested that in paired-click paradigm $\mathrm{N}_{100}$ could reflect initial direction of attention, and $\mathrm{P}_{200}$ reflects early allocation of attention, initial conscious experience, and entrance into working memory of the stimulus [31, 62, 63]. Therefore, women in the current study might be more alert, reflected by larger $\mathrm{N}_{100}$ amplitudes than men both to $S_{1}$ and $S_{2}$. And in the end, women allocated more attention resources to relevant information than men, reflected by significantly larger $S_{1} \mathrm{P}_{200}$ amplitude for females than males. Additionally, the current study also indicated that CPS disrupted allocation of attention resources, reflected by attenuated activation during $\mathrm{P}_{200}$ time window for both clicks after CPS than control procedures, which was in accordance with the majority of the findings in attention studies, and should involve the mechanism that acute stress impairs normal selective attention via disruptions of higher PFC functions (as a review, see [64]).

As for the effects of acute stress on sensory gating of $\mathrm{N}_{100}$ and $\mathrm{P}_{200}$, the current study found no stress effect, which was in accordance with Ermutlu et al. [29]. However, White et al. [12] using mental arithmetic stressor reported disrupted $\mathrm{N}_{100}$ gating ratios. In typical paired-click paradigm, only pairs of identical clicks are presented and cognitive processing resources are always sufficient. This might be a possible explanation for no effect of CPS on $\mathrm{N}_{100}$ amplitude and gating indices in Ermutlu et al. [29] and this current study, but significant stress effects on $\mathrm{N}_{100}$ response and gating ratio in White et al. [12] because of the potential inadequate process resources allocated in paired-click listening task due to concurrent mental arithmetic processing and the impairment of inhibition function due to stressful situation.

At last, the data showed significantly longer latencies to $S_{1}$ than $S_{2}$ both for $\mathrm{N}_{100}$ and $\mathrm{P}_{200}$ and a similar trend for $\mathrm{P}_{50}$ although not statistically significant in this current study, which were in accordance with former studies [10, 23, 24, $65]$. We cannot interpret the results properly due to scarcity of relevant documents. Probably, peak latencies reflect the depth of information processing and cognitive process to $S_{2}$ is incomplete because of sensory gating, and as a result, the latency to $S_{1}$ is longer than $S_{2}$. The data of this study also showed a trend of longer $\mathrm{N}_{100}$ latencies for men than women, and it might be the fact that the depth of cognitive process during $\mathrm{N}_{100}$ time window was less for women than men, although as mentioned earlier, women might be more alert and allocate more attention resources to relevant information than men, according to larger $\mathrm{N}_{100}$ and $\mathrm{P}_{200}$ amplitudes than men both to $S_{1}$ and $S_{2}$. In a word, peak latencies in the pairedclick paradigm need more concerns and relevant data need to be better understood in the future, but at least the current latency data are in accordance with former studies, which assures in some extent that the components of $\mathrm{P}_{50}, \mathrm{~N}_{100}$, and $\mathrm{P}_{200}$ are extracted precisely.

As for the application of paired-click paradigm in neural pathological studies, based on this study, more emphasis should be paid on the control of all kinds of factors that might induce subjects a stressful state, and we suggest the importance of monitoring stress and anxiety levels of subjects, and furthermore, $\mathrm{N}_{100}$ and $\mathrm{P}_{200}$ gating indices should be cautiously used because of their strong correlations with high-order cognitive process. But no matter how does one think of the applications of the $\mathrm{P}_{50}, \mathrm{~N}_{100}$, and $\mathrm{P}_{200}$ sensory gating in pathological fields, the primary focus of the work is to standardize the recording of gating data and the extracting procedure of the components.

\section{Data Availability}

All data included in this study are available upon request by contact with the corresponding author.

\section{Conflicts of Interest}

The authors declare that there are no competing financial interests.

\section{Authors' Contributions}

ZX, HL, and YL designed the study; ZX, SG, and WW did the experiments and analyzed the data. ZX, YL, and SG wrote the paper. Zengyou Xin and Simeng Gu contributed equally to this paper.

\section{Acknowledgments}

This study is supported by the following: Shenzhen-Hong Kong Institute of Brain Science-Shenzhen Fundamental Research Institutions (2019SHIBS0003); National Natural Science Foundation of China (31871130 and 31671150); Guangdong Key Project (2018B030335001); Guangdong Major Program (2016KZDXM009); Innovative Team Program in Higher Education of Guangdong (2015KCXTD009); Fujian Provincial Department of Education Projects (JA15320); Shenzhen Basic Research Scheme (JCYJ20150729104249783); and Shenzhen Peacock Plan (KQTD2015033016104926).

\section{References}

[1] L. Elling, C. Steinberg, A.-K. Bröckelmann, C. Dobel, J. Bölte, and M. Junghofer, "Acute stress alters auditory selective attention in humans independent of HPA: a study of evoked potentials," PLoS One, vol. 6, no. 4, article e18009, 2011.

[2] S. Gu, W. Wang, F. Wang, and J. H. Huang, "Neuromodulator and emotion biomarker for stress induced mental disorders," Neural Plasticity, vol. 2016, Article ID 2609128, 6 pages, 2016.

[3] E. J. Hermans, H. J. F. van Marle, L. Ossewaarde et al., "Stressrelated noradrenergic activity prompts large-scale neural network reconfiguration," Science, vol. 334, no. 6059, pp. 11511153, 2011.

[4] V. Lai, C. Theppitak, T. Makizuka et al., "A normal intensity level of psycho-physiological stress can benefit working memory performance at high load," International Journal of Industrial Ergonomics, vol. 44, no. 3, pp. 362-367, 2014.

[5] C. Kirschbaum, K. M. Pirke, and D. H. Hellhammer, "The 'Trier Social Stress Test'-a tool for investigating 
psychobiological stress responses in a laboratory setting," Neuropsychobiology, vol. 28, no. 1-2, pp. 76-81, 1993.

[6] M. J. Brinkman and J. E. Stauder, "Development and gender in the P50 paradigm," Clinical Neurophysiology, vol. 118, no. 7, pp. 1517-1524, 2007.

[7] G. Zouridakis and N. N. Boutros, "Stimulus parameter effects on the P50 evoked response," Biological Psychiatry, vol. 32, no. 9, pp. 839-841, 1992.

[8] R. Freedman, L. E. Adler, G. A. Gerhardt et al., "Neurobiological studies of sensory gating in schizophrenia," Schizophrenia Bulletin, vol. 13, no. 4, pp. 669-678, 1987.

[9] L. Jones, P. Hills, K. Dick, S. Jones, and P. Bright, "Cognitive mechanisms associated with auditory sensory gating," Brain and Cognition, vol. 102, pp. 33-45, 2016.

[10] W. P. Hetrick, C. A. Sandman, W. E. Bunney, Y. Jin, S. G. Potkin, and M. H. White, "Gender differences in gating of the auditory evoked potential in normal subjects," Biological Psychiatry, vol. 39, no. 1, pp. 51-58, 1996.

[11] A. J. Woods, J. W. Philbeck, K. Chelette, R. D. Skinner, E. Garcia-Rill, and M. Mennemeier, "f," Acta Neurobiologiae Experimentalis, vol. 71, no. 3, pp. 348-358, 2011.

[12] P. M. White, A. Kanazawa, and C. M. Yee, "Gender and suppression of mid-latency ERP components during stress," Psychophysiology, vol. 42, no. 6, pp. 720-725, 2005.

[13] A. Brockhaus-Dumke, R. Mueller, U. Faigle, and J. Klosterkoetter, "Sensory gating revisited: relation between brain oscillations and auditory evoked potentials in schizophrenia," Schizophrenia Research, vol. 99, no. 1-3, pp. 238-249, 2008.

[14] J. V. Patterson, W. P. Hetrick, N. N. Boutros et al., "P50 sensory gating ratios in schizophrenics and controls: a review and data analysis," Psychiatry Research, vol. 158, no. 2, pp. 226-247, 2008.

[15] T. Popov, T. Jordanov, N. Weisz, T. Elbert, B. Rockstroh, and G. A. Miller, "Evoked and induced oscillatory activity contributes to abnormal auditory sensory gating in schizophrenia," NeuroImage, vol. 56, no. 1, pp. 307-314, 2011.

[16] C. M. Yee, T. J. Williams, P. M. White, K. H. Nuechterlein, D. Ames, and K. L. Subotnik, "Attentional modulation of the P50 suppression deficit in recent-onset and chronic schizophrenia," Journal of Abnormal Psychology, vol. 119, no. 1, pp. 31-39, 2010.

[17] B. A. Clementz, M. A. Geyer, and D. L. Braff, "Poor P50 suppression among schizophrenia patients and their first-degree biological relatives," American Journal of Psychiatry, vol. 155, no. 12, pp. 1691-1694, 1998.

[18] R. Karkal, N. Goyal, S. K. Tikka, R. V. Khanande, A. Kakunje, and C. R. J. Khess, "Sensory gating deficits and their clinical correlates in drug-free/drug-naive patients with schizophrenia," Indian Journal of Psychological Medicine, vol. 40, no. 3, pp. 247-256, 2018.

[19] R. D. Franks, L. Adler, M. Waldo, J. Alpert, and R. Freedman, "Neurophysiological studies of sensory gating in mania: comparison with schizophrenia," Biological Psychiatry, vol. 18, no. 9, pp. 989-1005, 1983.

[20] R. Freedman, L. E. Adler, and M. Waldo, "Gating of the auditory evoked potential in children and adults," Psychophysiology, vol. 24, no. 2, pp. 223-227, 1987.

[21] L. Rasco, R. D. Skinner, and E. Garcia-Rill, "Effect of age on sensory gating of the sleep state-dependent P1/P50 midlatency auditory evoked potential," Sleep Research Online, vol. 3, no. 3, pp. 97-105, 2000.
[22] B. A. Clementz and L. D. Blumenfeld, "Multichannel electroencephalographic assessment of auditory evoked response suppression in schizophrenia," Experimental Brain Research, vol. 139, no. 4, pp. 377-390, 2001.

[23] D. R. Fuerst, J. Gallinat, and N. N. Boutros, "Range of sensory gating values and test-retest reliability in normal subjects," Psychophysiology, vol. 44, no. 4, pp. 620-626, 2007.

[24] M. Lijffijt, F. G. Moeller, N. N. Boutros et al., "The role of age, gender, education, and intelligence in P50, N100, and P200 auditory sensory gating," Journal of Psychophysiology, vol. 23, no. 2, pp. 52-62, 2009.

[25] C. Thomas, I. vom Berg, A. Rupp et al., "P50 gating deficit in Alzheimer dementia correlates to frontal neuropsychological function," Neurobiology of Aging, vol. 31, no. 3, pp. 416-424, 2010.

[26] M. R. Johnson and L. E. Adler, "Transient impairment in P50 auditory sensory gating induced by a cold-pressor test," Biological Psychiatry, vol. 33, no. 5, pp. 380-387, 1993.

[27] P. M. White and C. M. Yee, "Effects of attentional and stressor manipulations on the P50 gating response," Psychophysiology, vol. 34, no. 6, pp. 703-711, 1997.

[28] C. M. Yee and P. M. White, "Experimental modification of P50 suppression,” Psychophysiology, vol. 38, no. 3, pp. 531-539, 2001.

[29] M. N. Ermutlu, S. Karamürsel, E. H. Ugur, L. Senturk, and N. Gokhan, "Effects of cold stress on early and late stimulus gating," Psychiatry Research, vol. 136, no. 2-3, pp. 201-209, 2005.

[30] R. M. Atchley, Mindfulness Meditation Reduces Stress-Related Inhibitory Gating Impairment, Bowling Green State University, 2014.

[31] K. Gjini, S. Burroughs, and N. N. Boutros, "Relevance of attention in auditory sensory gating paradigms in schizophrenia," Journal of Psychophysiology, vol. 25, no. 2, pp. 60-66, 2011.

[32] M. Kurthen, P. Trautner, T. Rosburg et al., "Towards a functional topography of sensory gating areas: invasive P50 recording and electrical stimulation mapping in epilepsy surgery candidates," Psychiatry Research: Neuroimaging, vol. 155, no. 2, pp. 121-133, 2007.

[33] A. Gasbarri, A. Pompili, A. d'Onofrio, A. Cifariello, M. C. Tavares, and C. Tomaz, "Working memory for emotional facial expressions: role of the estrogen in young women," Psychoneuroendocrinology, vol. 33, no. 7, pp. 964-972, 2008.

[34] V. Kumari, J. Konstantinou, A. Papadopoulos et al., "Evidence for a role of progesterone in menstrual cycle-related variability in prepulse inhibition in healthy young women," Neuropsychopharmacology, vol. 35, no. 4, pp. 929-937, 2010.

[35] J. M. Goldstein, M. Jerram, B. Abbs, S. Whitfield-Gabrieli, and N. Makris, "Sex differences in stress response circuitry activation dependent on female hormonal cycle," Journal of Neuroscience, vol. 30, no. 2, pp. 431-438, 2010.

[36] M. R. Milad, M. A. Zeidan, A. Contero et al., "The influence of gonadal hormones on conditioned fear extinction in healthy humans," Neuroscience, vol. 168, no. 3, pp. 652-658, 2010.

[37] X. Du and B. Jansen, "A neural network model of normal and abnormal auditory information processing," Neural Networks, vol. 24 , no. 6, pp. 568-574, 2011.

[38] H. Terada, T. Kurayama, K. Nakazawa, D. Matsuzawa, and E. Shimizu, "Transcranial direct current stimulation (tDCS) on the dorsolateral prefrontal cortex alters P50 gating," Neuroscience Letters, vol. 602, pp. 139-144, 2015. 
[39] E. J. Hermans, M. J. Henckens, M. Joëls, and G. Fernández, "Dynamic adaptation of large-scale brain networks in response to acute stressors," Trends in Neurosciences, vol. 37, no. 6, pp. 304-314, 2014.

[40] B. S. McEwen and J. H. Morrison, "The brain on stress: vulnerability and plasticity of the prefrontal cortex over the life course," Neuron, vol. 79, no. 1, pp. 16-29, 2013.

[41] N. N. Boutros, K. Gjini, S. B. Eickhoff, H. Urbach, and M. E. Pflieger, "Mapping repetition suppression of the P50 evoked response to the human cerebral cortex," Clinical Neurophysiology, vol. 124, no. 4, pp. 675-685, 2013.

[42] A. Brockhaus-Dumke, F. Schultze-Lutter, R. Mueller et al., "Sensory gating in schizophrenia: P50 and N100 gating in antipsychotic-free subjects at risk, first-episode, and chronic patients," Biological Psychiatry, vol. 64, no. 5, pp. 376-384, 2008.

[43] J.-C. Shan, M. H. Hsieh, C.-M. Liu, M.-J. Chiu, F.-S. Jaw, and H.-G. Hwu, "More evidence to support the role of S2 in P50 studies," Schizophrenia Research, vol. 122, no. 1-3, pp. 270$272,2010$.

[44] C. Kirschbaum, B. M. Kudielka, J. Gaab, N. C. Schommer, and D. H. Hellhammer, "Impact of gender, menstrual cycle phase, and oral contraceptives on the activity of the hypothalamuspituitary-adrenal axis," Psychosomatic Medicine, vol. 61, no. 2, pp. 154-162, 1999.

[45] B. M. Kudielka and C. Kirschbaum, "Sex differences in HPA axis responses to stress: a review," Biological Psychology, vol. 69, no. 1, pp. 113-132, 2005.

[46] D. Watson, L. A. Clark, and A. Tellegen, "Development and validation of brief measures of positive and negative affect: the PANAS scales," Journal of Personality and Social Psychology, vol. 54, no. 6, pp. 1063-1070, 1988.

[47] A. Beck, R. Steer, and G. Brown, Beck Depression Inventory-II, 1996.

[48] D. T. L. Shek, “The Chinese version of the State-Trait Anxiety Inventory: its relationship to different measures of psychological well-being," Journal of Clinical Psychology, vol. 49, no. 3, pp. 349-358, 1993.

[49] Y. Yang, D. Koh, V. Ng et al., "Self perceived work related stress and the relation with salivary IgA and lysozyme among emergency department nurses," Occupational and Environmental Medicine, vol. 59, no. 12, pp. 836-841, 2002.

[50] J. Rentzsch, M. C. Jockersscherübl, N. N. Boutros, and J. Gallinat, "Test-retest reliability of P50, N100 and P200 auditory sensory gating in healthy subjects," International Journal of Psychophysiology, vol. 67, no. 2, pp. 81-90, 2008.

[51] P. R. Zoladz, D. M. Peters, C. E. Cadle et al., "Post-learning stress enhances long-term memory and differentially influences memory in females depending on menstrual stage," Acta Psychologica, vol. 160, pp. 127-133, 2015.

[52] E. R. De Kloet, M. Joëls, and F. Holsboer, "Stress and the brain: from adaptation to disease," Nature Reviews Neuroscience, vol. 6, no. 6, pp. 463-475, 2005.

[53] R. T. Knight, W. R. Staines, D. Swick, and L. L. Chao, "Prefrontal cortex regulates inhibition and excitation in distributed neural networks," Acta Psychologica, vol. 101, no. 2-3, pp. 159-178, 1999.

[54] O. Korzyukov, M. E. Pflieger, M. Wagner et al., "Generators of the intracranial P50 response in auditory sensory gating," NeuroImage, vol. 35, no. 2, pp. 814-826, 2007.

[55] J. R. Tregellas, D. B. Davalos, D. C. Rojas et al., "Increased hemodynamic response in the hippocampus, thalamus and prefrontal cortex during abnormal sensory gating in schizophrenia," Schizophrenia Research, vol. 92, no. 1-3, pp. 262272, 2007.

[56] T. J. Williams, K. H. Nuechterlein, K. L. Subotnik, and C. M. Yee, "Distinct neural generators of sensory gating in schizophrenia," Psychophysiology, vol. 48, no. 4, pp. 470-478, 2011.

[57] R. C. Gur, F. Gunning-Dixon, W. B. Bilker, and R. E. Gur, "Sex differences in temporo-limbic and frontal brain volumes of healthy adults," Cerebral Cortex, vol. 12, no. 9, pp. 998-1003, 2002.

[58] J. M. Goldstein, M. Jerram, R. Poldrack et al., "Hormonal cycle modulates arousal circuitry in women using functional magnetic resonance imaging," Journal of Neuroscience, vol. 25, no. 40, pp. 9309-9316, 2005.

[59] I. Griskova-Bulanova, J. Paskevic, K. Dapsys, V. Maciulis, O. Ruksenas, and S. M. Arnfred, "The level of arousal modulates P50 peak amplitude," Neuroscience Letters, vol. 499, no. 3, pp. 204-207, 2011.

[60] E. Kajantie and D. I. Phillips, "The effects of sex and hormonal status on the physiological response to acute psychosocial stress," Psychoneuroendocrinology, vol. 31, no. 2, pp. 151178, 2006.

[61] M. A. Farage, T. W. Osborn, and A. B. Maclean, "Cognitive, sensory, and emotional changes associated with the menstrual cycle: a review," Archives of Gynecology and Obstetrics, vol. 278, no. 4, pp. 299-307, 2008.

[62] M. Lijffijt, S. D. Lane, S. L. Meier et al., "P50, N100, and P200 sensory gating: relationships with behavioral inhibition, attention, and working memory," Psychophysiology, vol. 46, no. 5, pp. 1059-1068, 2009.

[63] A. C. Swann, M. Lijffijt, S. D. Lane et al., "Pre-attentive information processing and impulsivity in bipolar disorder," Journal of Psychiatric Research, vol. 47, no. 12, pp. 1917-1924, 2013.

[64] Z. Jafari, B. E. Kolb, and M. H. Mohajerani, "Effect of acute stress on auditory processing: a systematic review of human studies," Reviews in the Neurosciences, vol. 28, no. 1, pp. 113, 2017.

[65] G. S. Moura, Y. Trinanes-Pego, and M. T. Carrillo-de-la-Pena, "Effects of stimuli intensity and frequency on auditory p50 and n100 sensory gating," in Brain Inspired Cognitive Systems 2008, Advances in Experimental Medicine and Biology, vol 657, A. Hussain, I. Aleksander, L. Smith, A. Barros, R. Chrisley, and V. Cutsuridis, Eds., Springer, New York, NY, 2010. 